\title{
Accreditation and Assessment: The Basics for Nuclear Medicine Technology Educators
}

\author{
Penni A. Longenecker, CNMT \\ Pennsylvania College of Health Sciences, Lancaster, Pennsylvania
}

This article presents a high-level overview of accreditation and assessment in higher education and is designed to provide nuclear medicine technology educators with a foundational knowledge of this topic. This foundation will help educators understand accreditation and assessment at the college or university level and the program level by discussing key terminology and exploring the concept of a culture of assessment.

Key Words: accreditation; assessment; educators

J Nucl Med Technol 2019; 47:35-38

DOI: 10.2967/jnmt.118.219113

\section{$\mathbf{M}$}

ost new program directors and clinical coordinators have spent their career honing their talents and skills in the clinical aspects of nuclear medicine technology (NMT). They are often recognized for their communication skills and commitment to the profession. New NMT educators quickly realize they must develop parallel skills and competencies as an educator. Two areas of expertise that are imperative to the NMT educator are accreditation and assessment. These 2 topics are intertwined and can be overwhelming and intimidating to seasoned, as well as new, NMT faculty. Accreditation and assessment come with a language of their own. Also, each college and university adopts institutionspecific terminology and acronyms, which can confuse new faculty members. The purpose of this article is to provide NMT educators with a foundational knowledge of accreditation and assessment. This foundation will help educators to understand accreditation and assessment at the college or university level and the program level by discussing key terminology and exploring the concept of a culture of assessment.

\section{WHAT IS ACCREDITATION?}

Accreditation is a process of peer review used to determine the extent to which an institution of higher education or a program meets a set of established standards. There are

Received Aug. 8, 2018; revision accepted Sep. 24, 2018.

For correspondence or reprints contact: Penni A. Longenecker, Pennsylvania

College of Health Sciences, 850 Greenfield Rd., Lancaster, PA 17601.

E-mail: pelongen@pacollege.edu

Published online Nov. 9, 2018.

COPYRIGHT (c) 2019 by the Society of Nuclear Medicine and Molecular Imaging. multiple parts to the accreditation process: preparation of a self-study document, peer review of the self-study, an onsite visit, and accreditation action based on the findings. Selfstudy is both a process and a document. The self-study process is designed to explore all aspects of an institution or program within the context of the accreditation standards. The self-study report is a concise document that summarizes the findings of the process. Accreditation organizations also provide monitoring through annual reports and progress reports (1).

There are 3 possible findings from an accreditation review, depending on the extent to which the institution or program is in compliance with the accreditation standards. First, the institution or program may receive commendation if standards are exceeded. Commendation highlights exemplary outcomes and practices of the institution or program. Second, an accreditation review may cite areas of noncompliance with the standards. Depending on the accreditation organization, identified areas of noncompliance with the standards are referred to as recommendations, requirements, or deficiencies. All areas of noncompliance must be addressed by the institution or program, usually within a limited period. Third, accreditation organizations may offer suggestions for improvement. In these instances, the institution or program is in compliance with the accreditation standards but has an opportunity for improvement. Suggestions do not have to be implemented and do not affect accreditation status.

There are 4 types of accreditations: regional, programmatic, national faith-related, and national career-related ( 1 ). In this article, the discussion is limited to regional and programmatic accreditation.

\section{Regional Accreditation}

Regional accreditation focuses its review at the college or university level and does not delve into details at the program level. There are currently 6 geographic regional accreditation organizations: the Higher Learning Commission (www.hlcommission.org), the Middle States Commission on Higher Education (www.msche.org), the New England Association of Schools and Colleges (www.neasc.org), the Northwest Commission on Colleges and Universities (www.nwccu.org), the Southern Association of Colleges and Schools Commission on Colleges (www.sacscoc.org), and the Western Association of Schools and Colleges (www. acswasc.org). 
Since institutions vary greatly, the accreditation review is considered within the context of the mission of a college or university. For example, the mission of a specialized college of health sciences would be quite different from the mission of a liberal arts college. However, each college will need to describe and provide evidence of how it meets each of the accreditation standards within the scope of its mission.

The number of standards (in some cases referred to as criteria) for each regional accreditation organization ranges from 5 to 14 . However, even with the wide range in the number of standards, the key areas of review are mission, integrity and ethics, curriculum, student support services, resources, leadership and governance, planning, and assessment. It is in the best interest of each NMT program director to have an understanding of the expectations the regional accreditation organization has for the college or university in which the NMT program exists. The accreditation status of each college or university is posted on the regional accreditation organization's webpage.

\section{Programmatic Accreditation}

Accreditation at the program level is referred to as programmatic, discipline-specific, or specialized accreditation. For this discussion, programmatic accreditation will be the terminology used. Although regional accreditation provides a review of institutional quality, programmatic accreditation adds another layer of quality assurance. It helps to substantiate that a particular program meets the expectations of the profession and prepares graduates in particular areas of expertise. In many professions, successful completion of an accredited program is required for certification or licensing examination eligibility. Examples include nursing, health sciences, and teaching professions. Each programmatic accreditation organization is uniquely designed to evaluate the quality of the program as compared with the standards established by the profession. However, a review of the standards from a variety of programmatic accreditation organizations reveals that they are not so different from the regional accreditation organizations and typically consider mission and outcomes, resources, policies and procedures, curriculum, and assessment.

NMT educational programs may seek accreditation through the Joint Review Committee on Educational Programs in Nuclear Medicine Technology (JRCNMT). Nuclear medicine educators may have experience with accreditation in clinical nuclear medicine departments, but most have not participated in accreditation associated with higher education. Therefore, for many NMT program directors, their first in-depth experience with accreditation occurs when they begin their self-study in preparation for initial or continuing accreditation with the JRCNMT. It is critical that all NMT program directors regularly reference the JRCNMT accreditation standards. On July 1, 2018, new standards went into effect. Each program director must review the new standards and determine what updates must be made to the program to come into compliance. For more information on the specifics of the JRCNMT accreditation standards and process, refer to www.jrenmt.org.

\section{ASSESSMENT}

Once reserved for the elite, access to a college education changed in 1944, when the GI Bill provided military personnel with funding to pursue higher education. The second big wave of governmental funding came with the 1965 Higher Education Act (2-4). It was the Title IV provisions of this act that provided expanded access to financial aid. This is why federal financial aid is often referred to as Title IV funds. Accreditation organizations, once charged only with ensuring the quality of education, also became gatekeepers to federal financial aid. By linking Higher Education Act Title IV funds to accreditation, the voluntary process of accreditation became critical to an institution's financial viability (2-4).

The current debate over the cost of a college education in relationship to the return on investment is not new. The assessment movement can be traced back to the 1980s in response to needs for reform in higher education. At the time, few colleges were eager to adopt a student learning outcomes perspective for assessment (5). However, in 1988, the U.S. Department of Education started requiring accreditation organizations to include outcomes assessment in their criteria for accreditation (2). This is the point in history where accreditation and outcomes assessment became intertwined. Like the multiple layers of accreditation in an institution of higher education, assessment follows a similar pattern. Assessment exists at the institutional, program, and course levels.

Early assessment cycles focused on inputs such as qualifications of faculty, books in the library, and quality of facilities, whereas current accreditation assessment focuses more on student learning outcomes. A college may have highly credentialed faculty and an amazing library, but the real question is whether the students are learning anything. Welldesigned assessment plans help to document mission fulfillment, student learning outcomes, continuous improvement activities, and substantial compliance with the accreditation standards.

\section{LEVELS OF ASSESSMENT}

\section{Institutional Assessment}

Institutional assessment is a collegewide endeavor that is typically designed to ensure the college is meeting the standards of the regional accreditation organization. In addition to meeting accreditation standards, institutional assessment is also intended to enhance institutional effectiveness. Most colleges and universities have a person or office that oversees the collegewide assessment process. Services of this office may include deploying alumni and employer surveys, conducting an assessment for a student retention initiative, and offering workshops on assessment. The offices typically 
have staff with a wide range of expertise who can serve as resources for program directors. Hospital-based NMT programs will not have these resources available but may be able to reach out to peers or the representatives at the accreditation organization for support.

Colleges and universities often have a framework or model to describe the overall institutional effectiveness strategy. It can include information about the various components of assessment across the college or university. This can provide program directors with insight into how their program's assessment process fits into the bigger picture of institutional effectiveness.

\section{Program-Level Assessment}

Program-level assessment is a way of determining whether graduates are meeting the overarching learning outcomes of the program. Each program must have a published, clearly stated, measurable set of outcomes for its graduates. Assessment tools are then designed to measure student achievement of program-level learning outcomes. Direct measures such as competencies, portfolios, and credentialing examination pass-rates are preferred. Indirect measures such as surveys, course grades, and retention rates may also be used. It may seem odd that grades are considered indirect measures of student learning. Course grades are indirect measures because they may include attendance and participation, vary by instructor, or be based on vague standards. Banta and Palomba describe a course grade as a "summary measure" that does not directly measure learning outcomes (6). There are, however, learning assessments within the course that contribute to the grade and are direct measures of student learning outcomes (6).

For example, a program may have a student learning outcome stating that the graduate will work effectively with members of the health care team. This outcome might be assessed at the program level by looking at aggregate data from sources such as clinical evaluation forms that assess students' demonstration of teamwork in the clinical environment; group projects in which classmates work together to complete the assignment, with the group work assessed using a rubric; employer surveys that ask if graduates contribute to the health care team; and alumni surveys that ask graduates if they contribute to the health care team.

Clinical evaluation forms are a direct measure of observable behavior. Surveys are indirect measures because they are based on opinion and perception. The key point is that a combination of direct and indirect measures is optimal whereas using only one type of assessment methodology is ill advised. The goal is to use this information to determine the extent to which the program is achieving its published learning outcomes and to inform meaningful program improvements.

\section{Course-Level Assessment}

Each course has an established course description and student learning outcomes that are typically reviewed and approved by a curriculum committee. Course-level assessment is a way of determining the effectiveness of the course in guiding student achievement of the learning outcomes. It is at the course level that faculty feel most familiar with assessment. Courses are designed to include assessment of student learning through quizzes and examinations, competency testing, research papers, projects, and other means. It is important to consider the type and variety of assessments, as well as the extent to which the assessments align with the intended course outcomes. Wehlburg suggests a simple grid to help an instructor determine whether course outcomes and learning assessments are aligned (7). Figure 1 adapts this suggestion for use with nuclear medicine courses.

The grid makes it easy to align course learning outcomes with the student learning assessments. This process could be done every 3-5 y or as part of a major course revision. The following are 3 of many possible scenarios that could be discovered through this exercise:

In scenario 1 , the course has 4 outcomes that are all assessed with a midterm and final multiple-choice examination. A possible course-level assessment finding might be that all outcomes are assessed using only one strategy. Because best practice in teaching suggests it is helpful to use a variety of assessment tools, the instructor should consider using additional assessment methodologies.

In scenario 2, the assessments seem appropriate, but the outcomes do not seem to be up to date with the current content and practice. This finding indicates the need to review and revise the course outcomes. Sometimes a new instructor inherits a course, and learning outcomes have not been reviewed or updated in a long time. Keep in mind that changing course outcomes typically requires approval outside the program, so the instructor should seek out a colleague or administrator for guidance on the proper steps and channels for making curricular revisions. Also, keep in mind that anytime course outcomes are changed, alignment with learning assessments should be checked.

In scenario 3, the assessments show that the students are not demonstrating effective learning relative to outcomes. This finding indicates a need to choose a different teaching approach, or to incorporate additional practice exercises, or to put more emphasis on this aspect of the course.

\section{CULTURE OF ASSESSMENT}

Assessment is a way for colleges to determine whether they are meeting their published institutional, program, and course outcomes. Although assessment is required by

\begin{tabular}{|l|l|l|l|}
\hline $\begin{array}{l}\text { Course: } \\
\text { NMT 101 }\end{array}$ & $\begin{array}{l}\text { Assignment/ } \\
\text { Learning } \\
\text { Assessment 1 }\end{array}$ & $\begin{array}{l}\text { Assignment/ } \\
\text { Learning } \\
\text { Assessment 2 }\end{array}$ & $\begin{array}{l}\text { Assignment/ } \\
\text { Learning } \\
\text { Assessment 3 }\end{array}$ \\
\hline Outcome \#1 & & & \\
\hline Outcome \#2 & & & \\
\hline Outcome \#3 & & & \\
\hline Outcome \#4 & & & \\
\hline
\end{tabular}

FIGURE 1. Template to review alignment of course outcomes and learning assessments. 
accreditation organizations, it is the educator's commitment to offering quality educational experiences for students that serves as the primary motivation.

A college or university creates a culture of assessment through a systematic, sustainable, ongoing assessment process. It is demonstrated through data-driven decision making and continuous improvement guided by assessment findings. Attention is given to providing the necessary resources, support, and professional development. This culture of ongoing assessment makes the accreditation process much easier because the evidence is gathered and documented on a regular basis, helping to avoid the panicked, episodic assessment approach that is inevitable in its absence (7).

At the heart of a culture of assessment is the motivation to pursue continuous growth and improvement. Times are turbulent in health care and education, and it is only through ongoing assessment that quality nuclear medicine education can be sustained.

Sometimes it is hard to know where to begin. NMT educators are already involved in many aspects of assessment. A program director might start by reflecting on the various assessment activities associated with the nuclear medicine program. The director can consider drawing a concept map or diagram to describe the key components of program assessment. To become part of the culture, assessment must be a regular, ongoing activity. Most educators in health sciences programs are attuned to the needs of their students and routinely make changes to processes, courses, and the program to better meet the learners' needs. Program faculty can enhance program assessment by documenting the changes they make throughout the year and the rationale for the changes. All of the various assessment activities should be reviewed to identify gaps, redundancies, and opportunities to create efficiencies. Partner with college and university assessment offices to look for opportunities to improve assessment processes. Wherever possible, the various assessment requirements should be aligned to minimize any duplication of efforts.

New faculty and advisory committee members should be oriented to the accreditation and assessment requirements for the nuclear medicine program. The advisory committee should be engaged in the assessment process. Assessment reports should be shared with the advisory committee, and comments, suggestions, and feedback should be sought. Opportunities to improve the NMT program should be discussed. "Assessment" should be made a standing agenda item for the advisory committee meetings. These are just a few of the opportunities to contribute to a culture of assessment within a program, department, and college.

\section{FINAL THOUGHTS}

Accreditation organizations face criticisms that range from being too rigid and stifling innovation to having a peer review process that is too lenient $(3,4,8)$. Despite the many criticisms of accreditation, it remains an efficient and cost-effective way of studying the quality of colleges and their educational programs. Accreditation may seem expensive, but the costs are kept lower in part by the many peer volunteers who review self-studies and conduct site evaluations.

Accreditation is an opportunity for program improvement and professional growth. A program director learns from the accreditation process. After participating in accreditation on the programmatic level, nuclear medicine educators should consider serving as a resource for colleagues in the process of initial and continuing accreditation. Or better yet, educators can volunteer to serve on a committee when the institution is in the process of peer review.

\section{DISCLOSURE}

Penni Longenecker serves as the chair of the JRCNMT Board of Directors; however, these are her observations and do not represent in any official manner the JRCNMT. No other potential conflict of interest relevant to this article was reported.

\section{REFERENCES}

1. Accreditation \& recognition in the United States. Council for Higher Education Accreditation website. https://www.chea.org/accreditation-recognition-united-states. Published November 15, 2015. Accessed December 12, 2018.

2. Lubinescu E, Ratcliff J, Gaffney M. Two continuums collide: accreditation and assessment. New Dir Higher Educ. 2001;2001:5-21.

3. Flood J, Roberts J. The evolving nature of higher education accreditation: legal considerations for institutional research leaders. New Dir Institutional Res. 2017;2016: 73-84.

4. Lindgrensavage C. Regulatory oversight of student financial aid through accreditation of institutions of higher education. J Law Educ. 2016;45:327-361.

5. Ewell PT. An emerging scholarship: a brief history of assessment. In: Banta TW, ed. Building a Scholarship of Assessment. San Francisco, CA: Jossey-Bass; 2002:3-25.

6. Banta TW, Palomba CA. Assessment Essentials: Planning, Implementing, and Improving Assessment in Higher Education. San Francisco, CA: Jossey-Bass; 1999:93-144, 163-165,

7. Wehlburg CM. Meaningful Course Revisions: Enhancing Academic Engagement Using Student Learning Data. San Francisco, CA: Jossey-Bass; 2006:15-16, 156-157.

8. Horn M, Dunagan A. Innovation and quality assurance in higher education. In: Phillips SD, Kinser K, eds. Accreditation on the Edge: Challenging Quality Assurance in Higher Education. Baltimore, MD: Johns Hopkins University Press; 2018: $82-101$. 